\title{
RELATION OF PER CAPITA INCOME AND GROSS DOMESTIC PRODUCT TO THE SUPPLY AND DISTRIBUTION OF PEDIATRICIANS IN THE UNITED STATES
}

\author{
Gary L. Freed, MD, mph, Tammie A. Nahra, PhD, John R. C. Wheeler, PhD, and The \\ Research Advisory Committee of the American Board of Pediatrics
}

Objective To describe the number and distribution of pediatricians per child nationally and on a state-by-state basis relative to the economic conditions within each state.

Study design Real inflation-adjusted gross domestic product (GDP) per capita (1996 dollars) was plotted against the number of all active physicians and pediatricians in the United States for all years data were available. GDP was then compared with the active number of pediatric medical physicians per child 0 to 14 years of age.

Results The number of pediatricians per 100,000 children has more than doubled, from 49.8 to 106.2. Since 1929, the growth in the total number of physicians per capita in the United States has followed a linear relation $\left(r^{2}=0.977\right)$ with per capita national GDP. This relation is consistent with that specifically for all pediatricians as well $\left(r^{2}=0.980\right)$ for the years in which data are available (1963 to 2000). There is an extremely uneven distribution of pediatricians. Income differences only partially explain this maldistribution.

Conclusions There has been a marked increase in the number of pediatricians relative to the number of children in the United States, correlating strongly with the rise in per capita GDP. However, there has been a furthering of their uneven distribution across the United States. (J Pediatr 2004;144:723-8)

$\mathbf{T}$ he appropriate number and distribution of physicians in the United States is an issue of great interest. ${ }^{1}$ Efforts to develop methods that describe and forecast the supply and distribution of the physician workforce have received significant attention. ${ }^{2}$ This study focuses on the supply and distribution of pediatricians in the United States. We describe trends in the number of pediatricians and in their current distribution across the nation. In addition, we focus on the key policy question of the extent to which per capita income is associated with the number and distribution of pediatricians in the United States. In particular, we consider both whether rising income is associated with an increase in the relative supply of pediatricians nationally and whether states with high per capita income enjoy a greater relative supply of pediatricians.

Cooper et $\mathrm{al}^{3}{ }^{3}$ using trend analysis, have shown that the absolute number of physicians in the United States has been closely correlated with the growth of the population as well as the economic growth of the nation. However, these analyses have not examined the number and distribution of physicians by specialty through the use of this economic paradigm. Furthermore, because of demographic changes in the United States over the last several decades, the proportion of the total population made up of children has fallen (US Census 2000). As such, it is unclear if the relation identified by Cooper et al applies when looking at the pediatric subset of the general population.

Concerns have also been raised regarding the distribution of pediatricians across the 50 states. Previous research most recently using data from the early 1990s has demonstrated wide variation in the supply of pediatricians around the United States. ${ }^{4}$ There have been some measures implemented to address this issue, but their cumulative impact is unknown. ${ }^{5}$

From the Child Health Evaluation and Research (CHEAR) Unit, Department of Health Management and Policy, Division of General Pediatrics, University of Michigan, Ann Arbor, Michigan, and the American Board of Pediatrics, Chapel Hill, North Carolina.

Supported by a grant from the American Board of Pediatrics Foundation.

Submitted for publication Sept 30, 2003; last revision received Jan 27, 2004; accepted Feb 17, 2004.

Reprint requests: Gary L. Freed, MD, $\mathrm{MPH}$, University of Michigan, 300 NIB 6E08, Ann Arbor, MI 48109-0456.

E-mail: gfreed@med.umich.edu. 0022-3476/\$ - see front matter

Copyright @ 2004 Elsevier Inc. All rights reserved.

10. 10 | 6/j.jpeds.2004.02.043 
This study examines the number and distribution of pediatricians both nationally and on a state-by-state basis relative to both the population of children and the economic conditions within each state.

\section{METHODS}

\section{Sources of Data}

Data on the number of self-designated pediatric generalist and subspecialist medical physicians over time and by practice locale were obtained from two sources of the American Medical Association (AMA): (1) the reference book Physician Characteristics and Distribution in the United States (1982 to 2002) and (2) the AMA Masterfile, which summarizes Doctors of Medicine (MD) counts by year, state, and physician self-designated practice specialty from 1978 to 2000. Included in these analyses are active medical (nonsurgical) pediatric physicians in office-based and hospital-based patient care activities as well as those in other professional activities, including administration, medical teaching, and research.

Annualized population counts and the number of children 0 to 14 years of age were obtained from the United States Census Bureau. Data for historic, real gross domestic product (GDP) and personal income per capita by state were obtained from the United States Bureau of Economic Analysis.

\section{Analysis Strategies}

To illustrate trend information on pediatric medical physician supply, two views are presented. First, the number of pediatric medical physicians is presented between the years 1978 and 2000. Second, to capture how pediatrician supply has changed in relation to the number of children 0 to 14 years of age, the number of pediatricians per 100,000 children is shown over the same time frame.

Next, this work applies a modified version of the physician workforce trend model developed by Cooper et al. ${ }^{3}$ One feature of the trend model is based on the relation between long-term economic forces and the demand for physician services. Cooper et al show that there exists a consistent and strong relation between economic expansion in developed countries (as measured by real inflation-adjusted GDP) and growth in the health care labor supply.

To capture visually the relation between economic growth and physician supply, real inflation-adjusted GDP per capita (1996 dollars) is plotted against the number of active physicians in the United States between 1929 and 2000. Similar plots focus on GDP and the number of pediatric medical physicians per capita. Pearson correlation coefficients $(r)$ for all plots show the strength of the linear relation between GDP and physician supply. Modifying this trend analysis one step further, GDP is then compared with the active number of pediatric medical physicians per child 0 to 14 years of age.

In the analysis of state-level data, a distribution of the number of pediatric medical physicians per 100,000 children are first presented to show state variation in physician density throughout the country. The 50 states are divided into quartiles representing those that are either less than or greater than $1 \mathrm{SD}$ above or below the median number of medical pediatricians per child.

The final graphic representation plots state-level real personal income per capita (1996 dollars) against the number of pediatric medical physicians for 1980 and 2000. Hereto, Pearson correlation coefficients are also presented to show the strength of the linear relation between relative state wealth and physician supply.

\section{RESULTS}

\section{Trends in Pediatrician Supply}

The absolute number of pediatricians (generalists and specialists) in the United States has increased by $140 \%$ during the years 1978 through 2000, from 25,872 to 62,049 (Fig 1). During that same time period, the population of children 0 to 14 years of age in the United States grew much more slowly. Therefore, the relative number of pediatricians per 100,000 children has more than doubled, from 49.8 to 106.2 pediatricians. $^{6}$

Figure 2 demonstrates that since 1929, the growth in the total number of physicians per capita in the United States has followed a close and consistent linear relation $(r=0.977)$ with per capita national GDP. This strong relation between physicians per capita and per capita GDP is consistent with that specifically for all pediatricians as well $(r=0.980)$ for the years in which data on pediatrician supply are available (1963 to 2000). This linear relation to per capita GDP also holds $(r=0.988)$ when looking at the growth in the number of pediatricians relative to the specific subset of the population of children 0 to 14 years of age (Fig 3 ). However, the slope of the line is steeper, indicating the number of pediatricians per capita has grown more rapidly relative to national per capita income for the prevalence of this specific age range of the population.

\section{Geographic Distribution of Pediatricians}

Without accounting for per capita income, there is an extremely uneven distribution of pediatricians across the 50 states. Figure 4 shows the state-by-state distribution of pediatricians relative to the population in each state. The distribution ranges from a high of 165 pediatricians per 100,000 children in Massachusetts, DC, to a low of 28 per 100,000 children in Idaho.

Differing income across the states is only a partial explanation for this maldistribution. Figure 5 shows the relation between per capita personal income by state and per capita pediatricians by state at two points in time, 1980 and 2000. For both years, the correlation between the number of pediatricians per 100,000 children and state per capita GDP is far lower than that found for the nation as a whole $(r=0.275$ and $r=0.427$, respectively, for 1980 and 2000). However, the increase in the slope of the trend line over that 20 -year period 


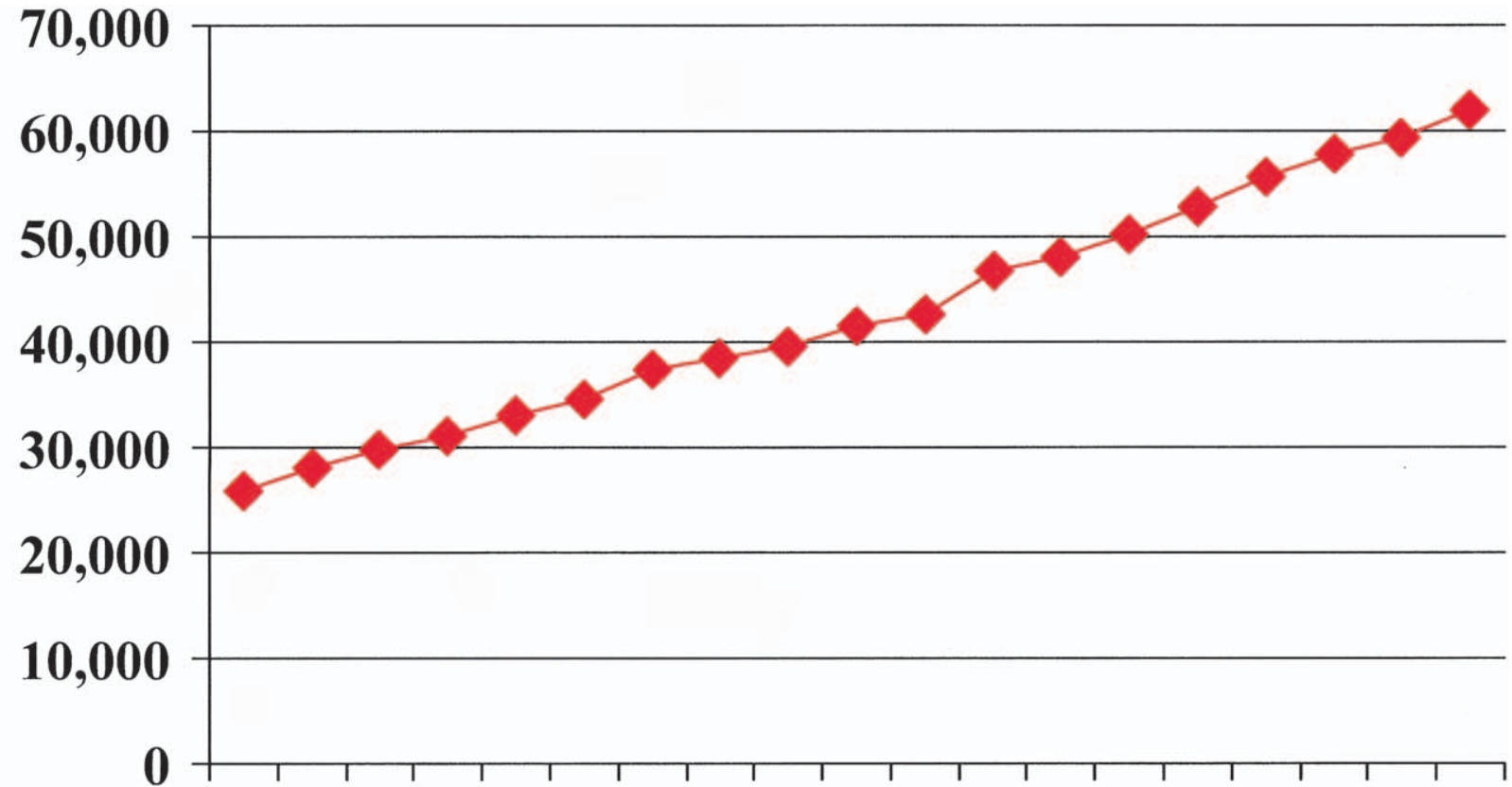

\#
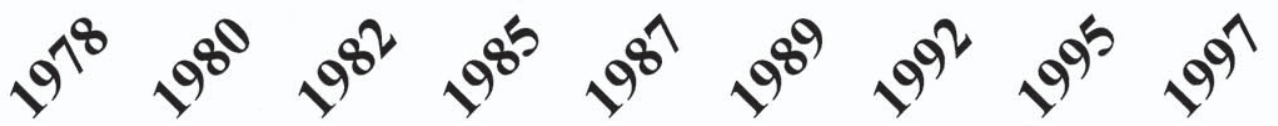

Fig I. Pediatric medical physicians, includes medical generalists and subspecialists. Sources: AMA Physician Masterfile; US Census Bureau.

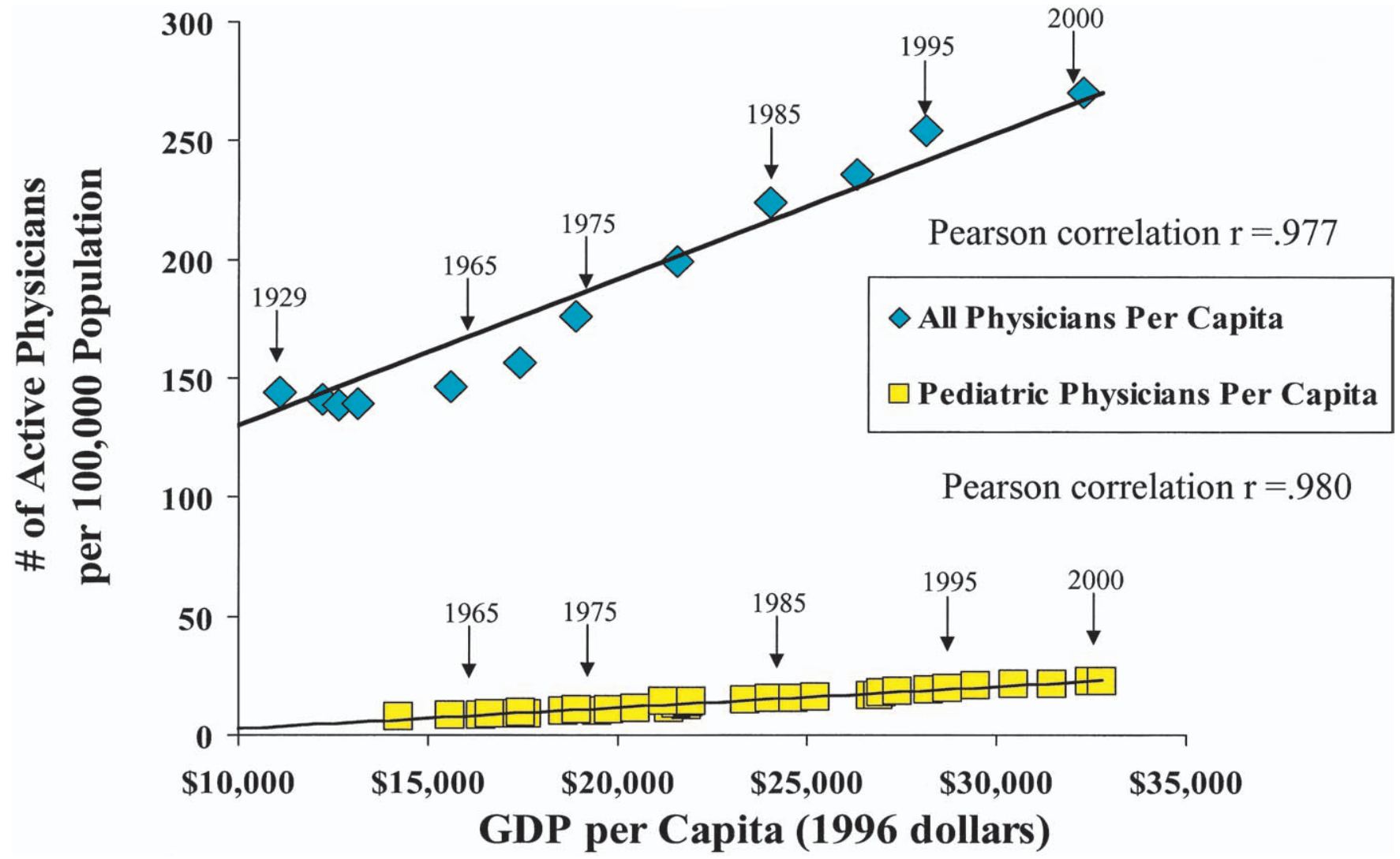

Fig 2. Active physicians per capita versus GDP per capita, includes all physicians and pediatric physicians. Sources: AMA Physician Masterfile; US Census Bureau; US Bureau of Economic Analysis. 


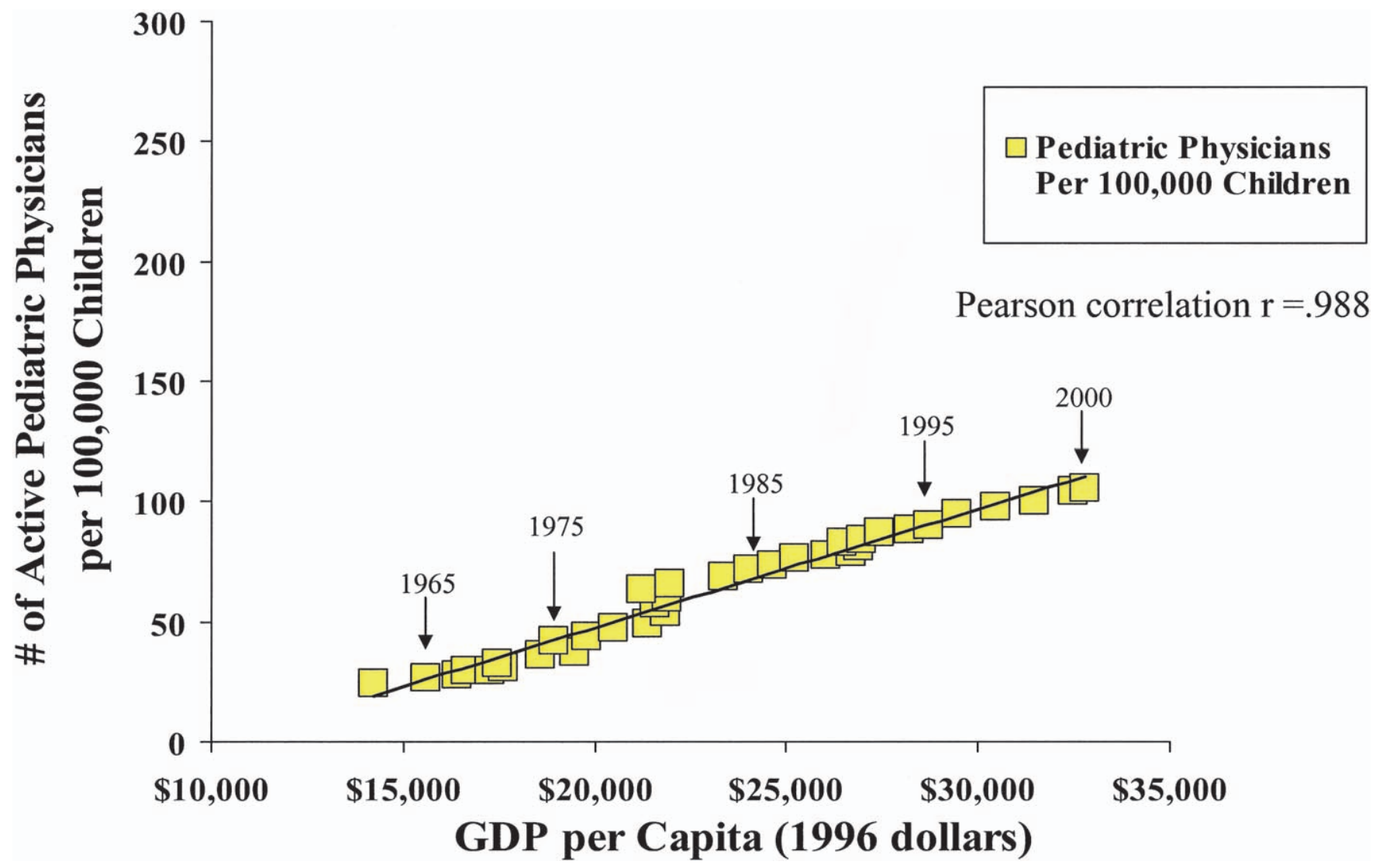

Fig 3. Pediatric medical physician per child vs GDP per capita (1963-2000). Sources: AMA Physician Masterfile; US Census Bureau; US Bureau of Economic Analysis.

indicates that pediatricians have been increasingly more likely to locate in states with higher per capita income.

\section{DISCUSSION}

There has been a marked increase in the number of pediatricians relative to the number of children in the United States, and the increase correlates strongly with the rise in the national per capita GDP. This indicates that for the country as a whole, as income has risen, so has the availability of pediatricians to our children.

We do not posit a cause-and-effect relation between economic expansion and pediatrician supply. However, from a societal perspective, a strong case can be made that pediatrician services represent a technical economic example of a "luxury," a term economists use to describe a good or service on which people prefer to spend a higher percentage of their money as their incomes rise. Indeed, for our nation as a whole, health care overall is a luxury good in this sense. As real per capita GDP has more than doubled over the past 40 years, the share of GDP going to purchase health care has risen steadily from $5.1 \%$ to $13.1 \%{ }^{7}$ As Getzen ${ }^{8}$ has documented, economic expansion is a dominant factor driving the use of health care and all physician services by the overall population.

The positive trend in the availability of pediatricians for the nation as a whole masks some important variation in the supply of pediatricians across the country. Indeed, the state with the most pediatricians per capita has nearly 7 times the number as the state with the lowest number of pediatricians per capita (Idaho). Newhouse et $\mathrm{al}^{7}$ linked uneven physician distribution with market forces but predicted it would improve concomitant with increased physician supply. However, our data indicate this has not been the case.

Our results form an extension of the work performed by Cooper et $\mathrm{al}^{3}$ demonstrating the association of national physician supply with national per capita GDP and overall US population. The same association at the national level was consistent when examining the pediatrician component of the physician workforce. When using the number of children in the United States rather than the total population, the strong correlation of pediatrician supply with national per capita GDP was maintained.

Our findings also expand on the results reported by Chang and Halfon ${ }^{4}$ that the pediatrician-to-child population ratio has continued to increase. Our study also provides an additional 7 years of data beyond Chang and Halfon (1993 to 1999), demonstrating the continuation of the trend seen in their study. Furthermore, our data demonstrate that the stateby-state variation in the per capita distribution of pediatricians they identified has become even more pronounced. Clearly, pediatricians have accelerated the trend toward concentrating in states with higher per capita GDP, and this trend has 


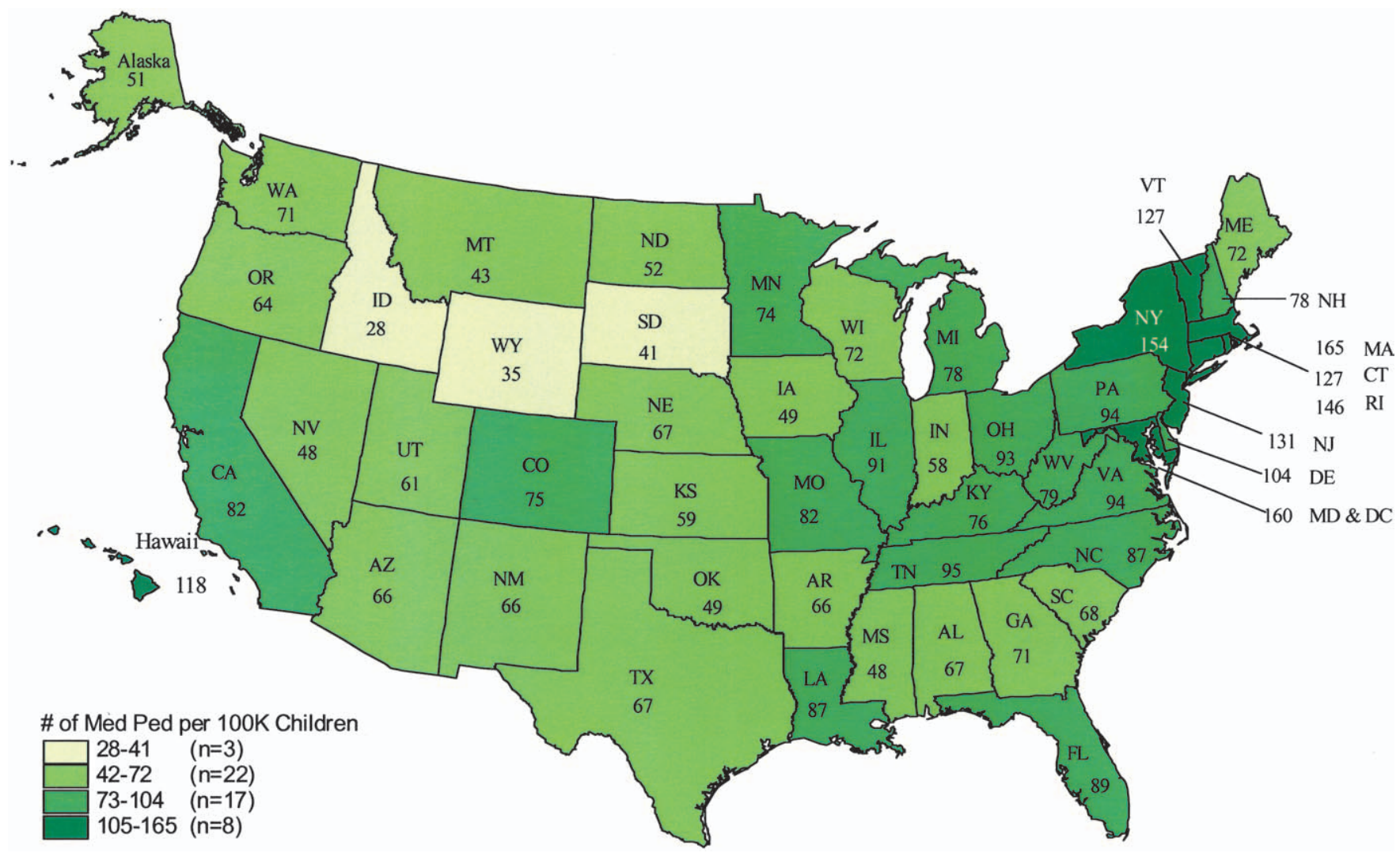

Fig 4. Pediatric medical physician distribution, medical pediatric physicians per 100,000 children (2000). Sources: AMA Physician Masterfile; US Census Bureau.

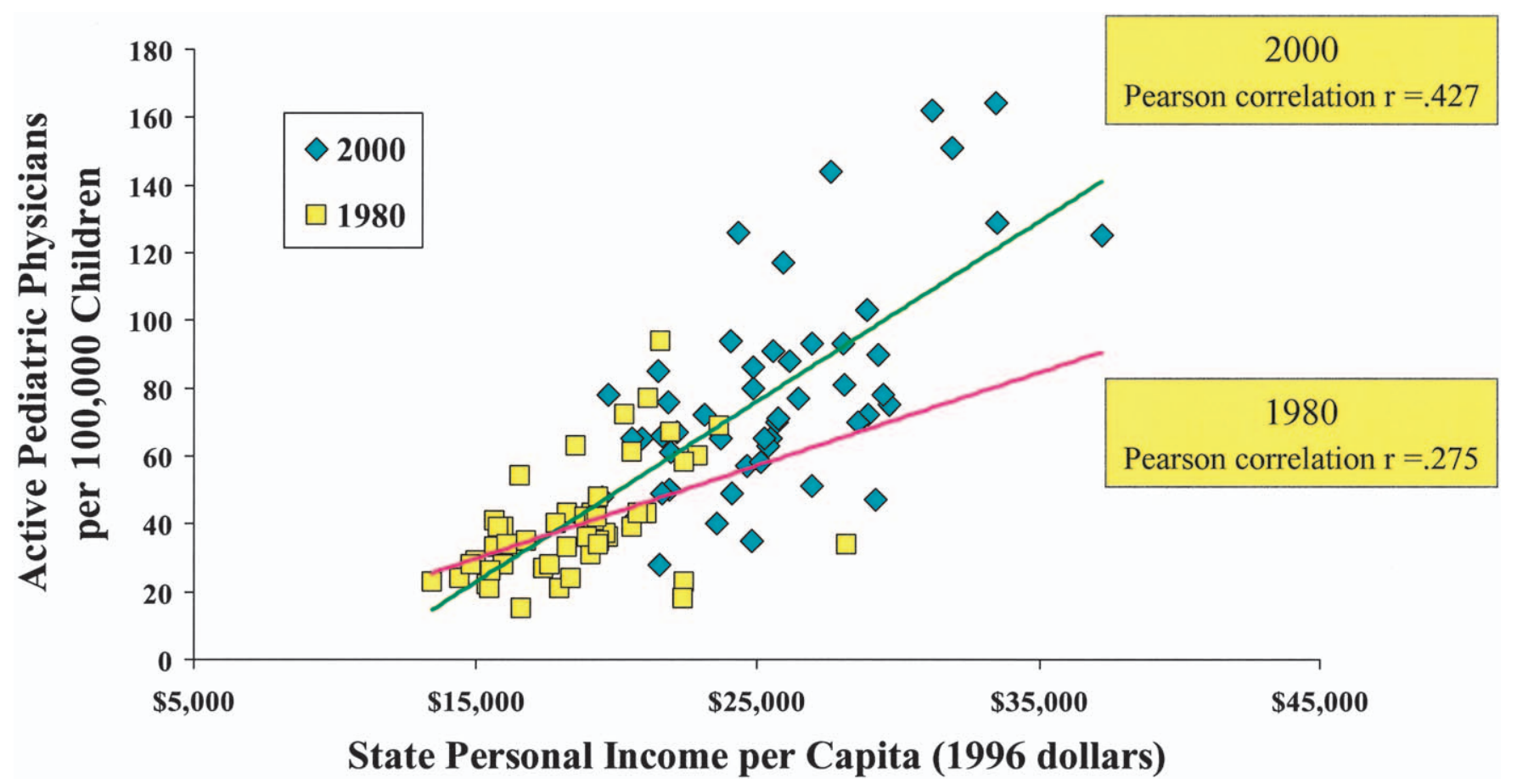

Fig 5. State personal income per capita versus state medical pediatric physician supply (1980 and 2000). Sources: AMA Physician Masterfile; US Census Bureau; US Bureau of Economic Analysis. 
remained constant despite transitions to managed care and other changes in the medical marketplace. It is likely that states with higher GDP also provide greater employment and economic opportunities for physicians.

Others have noted the apparent practice of physicians to gravitate toward opportunities that offer the potential for greater financial rewards. ${ }^{9}$ Termed the "white follows green law" by Mullan, it raises the issue of the ultimate ability of those who desire to use medical workforce policy to affect physician distribution without addressing geographic variation in physician compensation. ${ }^{2}$ Our study has not looked specifically at physician income levels. We are merely suggesting that states with higher per capita income present opportunities for physicians to earn higher incomes.

Poor geographic distribution of physicians was cited in the third report of the Council on Graduate Medical Education (COGME) as a barrier to improved quality of care and access for all Americans. ${ }^{10}$ For primary care physicians in general, studies have shown that increasing supply of these physicians is associated with lower mortality rates and diseasespecific death rates. ${ }^{11,12}$ With regard to pediatricians specifically, variation in their distribution may have significant implications regarding access to care for specific populations. For example, pediatricians are more likely than other physicians to participate in the federal Vaccines for Children (VFC) Program. ${ }^{10}$ As a growing segment of the pediatric population relies on this and other government safety net programs, areas with a smaller share of the pediatric workforce may have greater problems with access to care for children. There are also probable public health implications relative to variations in pediatrician distribution. LeBaron et $\mathrm{al}^{13}$ demonstrated a strong correlation of pediatrician distribution with immunization rates and delivery characteristics. Higher rates of immunization were seen in both the public and private immunization delivery sectors with increased numbers of pediatricians but not other primary care physicians.

There are also other factors that have been shown to be associated with physician choice of practice location. Several studies have demonstrated that new physicians are more likely to practice in states where they have finished their medical school or residency training. ${ }^{14-16}$ Although the Graduate Medical Education National Advisory Council (GMENAC) report recommended decentralizing medical education to improve distribution, such strategies have had a real but limited impact, as our results demonstrate. ${ }^{5}$

We are unable to determine if there are any variations in health outcomes as a result of the pattern of pediatrician distribution. Furthermore, our results do not take into account the part-time status or non-patient care-related activities of pediatricians or other physicians.
The AMA Masterfile is the most comprehensive listing of physicians in the United States, containing both members and nonmembers of the AMA. However, the self-designation of specialty and other factors result in an unknown degree of error in the use of this list.

In conclusion, despite significant and continued increases in the number of pediatricians in the workforce, there has been a furthering of their uneven distribution in the United States. Finally, it appears that even if the number of pediatricians in the United States will continue to rise, without some specific governmental policy to the contrary, this trend toward geographic concentration of the pediatric workforce will continue.

\section{REFERENCES}

1. Landro L. As specialists grow scarcer, families turn to telemedicine. In: Wall Street Journal Online; 2003. Available at: http://online.wsj.com.

2. Mullen F. Some thoughts on the white-follow-green law. Health Aff (Millwood) 2002;21:158-9.

3. Cooper RA, Getzen TE, McKee HJ, Laud P. Economic and demographic trends signal an impending physician shortage. Health Aff (Millwood) 2002;21:140-54.

4. Chang RK, Halfon N. Geographic distribution of pediatricians in the United States: an analysis of the fifty states and Washington, DC. Pediatrics 1997;100:172-9.

5. Adkins RJ, Anderson GR, Cullen TJ, Myers WW, Newman FS, Schwarz MR. Geographic and specialty distributions of WAMI Program participants and nonparticipants. J Med Educ 1987;62:810-7.

6. Freed GL, Nahra TA, Wheeler JRC. Predicting the pediatric workforce: use of trend analysis. J Pediatr 2003;143:570-5.

7. Newhouse J, Williams A, Schwartz W, Bennett B. The geographic distribution of physicians: Is the conventional wisdom correct? Santa Monica: RAND; 1982.

8. Getzen TE. Health care is an individual necessity and a national luxury: applying multilevel decision models to the analysis of health care expenditures. J Health Econ 2000;19:259-70.

9. Earnst R, Yett D. Econometric and statistical studies of the geographic distribution of physicians. In: Ernst RL, Yett DE, eds. Physician location and specialty choice. Ann Arbor (MI): Health Administration Press; 1985. p. $179-226$.

10. Santoli JM, Rodewald LE, Maes EF, Battaglia MP, Coronado VG. Vaccines for Children program, United States, 1997. Pediatrics 1999;104:e15. 11. Shi L, Starfield B. The effect of primary care physician supply and income inequality on mortality among blacks and whites in US metropolitan areas. Am J Public Health 2001;91:1246-50.

12. Rivo ML, Satcher D. Improving access to health care through physician workforce reform: directions for the 21st century. JAMA 1993;270:1074-8.

13. LeBaron CW, Massoudi M, Stevenson J, Lyons B. Vaccination coverage and physician distribution in the United States, 1997. Pediatrics 2001; 107:E31.

14. Watson C. The relationship between physician practice location and medical school area: an empiric model. Soc Sci Med 1980;14:63-9.

15. Wilensky G. Retention of medical student graduates: a case study of Michigan. In: Scheffler R, editor. Research in Health Economics. Greenwich: JAI Press; 1979.

16. Seifer SD, Vranizan K, Grumbach K. Graduate medical education and physician practice location: implications for physician workforce policy. JAMA 1995;274:685-91. 